\title{
I NNOVATIVE DESIGN MANAGEMENT AND DEVELOPMENT CONTROL CASE STUDY: NELSON MANDELA BAY METROPOLE - SOUTH AFRICA
}

doi> 10.4237/gtp.v5i3.178

\author{
Daniel KOEN \\ E-Space Homes, South Africa \\ |e-mail: ddkoen@mweb.co.za| \\ Francois THERON \\ Kanda Urban Design, South Africa \\ |e-mail: francois@kanda.co.za|
}

\begin{abstract}
Proposal: Intensive end-user research in the "Affordable Housing Sector" in R.S A. became necessary to find ways to counter ever increasing delivery costs and still satisfy preferences, quality and affordability. Research has to be followed up by innovative designs and lower cost and faster construction methods without forfeiting quality and aesthetics. Land cost and density design balanced with environmental quality became of utmost importance in any sustainable development. The same accounts for locality to achieve neighbourhood revitalization. A typical example is the Nelson Mandela Bay Metropole in South A frica where 100,000 dwellings need to be constructed in35 years to wipe out the back-log. The amount of data relating to a single dwelling is vast and with a large development even more significant. Traditionally the data is stored in diverse locations, for example, with government authorities, architects or other professionals, a developer, sub-contractor, conveyancer, financial institution or owner. Substantial delays and inefficiency result if existing data cannot be accessed rapidly, or at all. An electronic spatial process and data control system that is uniquely and physically associated with a particular house was successfully developed to address most of the problems we experienced.
\end{abstract}

Keywords: South Africa, Affordable Housing, Affordability, Development, Land, Sustainability, Quality, Design, Control, Nelson Mandela Bay Metropole. 


\section{I NTRODUCTI ON}

South Africa with its political history has divided cities with an urban sprawl with high transport and environmental costs on the one hand and on the other hand we have isolated townships and low cost areas with rows of standardized box-like houses on squaregrid layouts with minimal facilities and services.

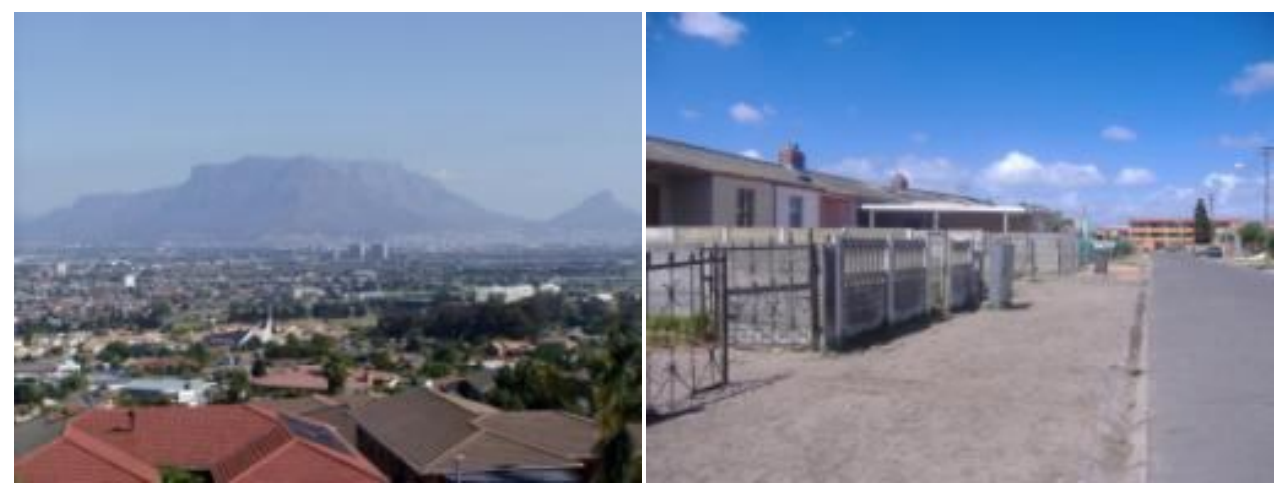

I mage 1: Urban Sprawl | I mage 2: I solated Township

Certain areas furthermore have wide spread poverty and high levels of unemployment in vast peripheral informal settlements.

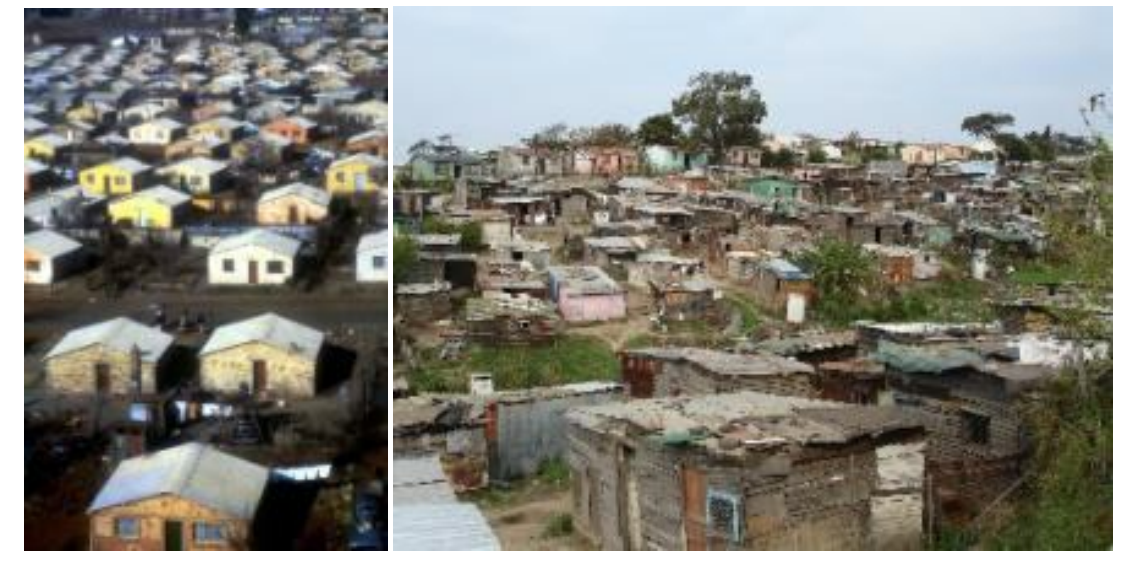

I mage 3: Low-Cost Housing | I mage 4: I nformal Settlements

A back log of more than 2 million homes exists in South Africa.

Because of several reasons, delivery is not fast enough.

Affordability has become a major stumbling block in the delivery process because of ever increasing costs.

A shortage of skilled labour and the energy crisis in South Africa also play a major role in the failure to deliver. 
High volume developments with increased densities can improve the delivery process; however it brings with it the need for new construction systems with faster turn around time.

That in turn requires the development and use of new technology to ensure good quality control and the ability to handle vast amounts of information characterized by large volume developments.

Lastly a holistic approach embracing all principles is necessary when it comes to the planning and design of the urban framework to improve and eventually overcome the historic imbalances in housing in South Africa.

The Nelson Mandela Bay Municipality devised a planning method called Sustainable Community Unit Planning, which fills the planning gap that existed between Spatial Development Framework Planning and the more detailed layout planning of high volume developments.

Our paper deals mainly with the planning and design process of a high volume development of more than 5,000 units over 4 years in the Nelson Mandela Bay Metropole, called Hillside in Despatch, and which we believe will be urban revitalization and integration at its best.

The amount of data relating to a single dwelling is significant and with a large development it is vast. Traditionally, the data is stored in diverse locations, for example, with government authorities, architects or other professionals, a developer, sub-contractor, conveyancer, financial institution or owner.

Substantial delays and in-efficiency result if existing data cannot be accessed rapidly, or at all.

E-space homes successfully patented and developed an electronic spatial process and data control system that is uniquely and physically associated with a particular house to address most of the problems we experienced in the past and expect to experience with our large volume devel opments discussed above.

The system has been branded space-key which, for the first time, gives a home an ID called homeID. 


\section{THE SITUATION}

\subsection{AFFORDABI LI TY}

Increases in input cost of land, services and top structures currently play a major role in affordability of end-users in the "Affordable Housing" market in South Africa.

Amongst other factors, this trend impacts seriously on the sustainability of development projects.

The lower to middle income group forms a large part of the abovementioned market segment (more than 60\%). This market is increasingly becoming affordability driven and lean architectural design and design management is necessary to fulfil the needs of this market segment in a sustainable manner, without forfeiting other design principles

\subsection{BACKLOG}

There is currently a huge backlog in delivery of affordable housing in South Africa (more than 2 million)

A typical example is the Nelson Mandela Bay Metropole in South Africa where 100,000 specially designed dwellings of high architectural and engineering quality need to be constructed over the next couple of years to wipe out the back-log.

\subsection{END-USER MARKET RESEARCH}

Since very little, if any, interaction exists between potential buyers and the design team, intensive research is required to determine inter-alia affordability and preferences of end-users. Only when these parameters have been established, can the designs of a lay-out plan and top-structure plans be conceptualized for a particular development.

\subsection{LACK OF HIGH VOLUME DEVELOPMENTS}

The demand for affordable homes is much larger than the supply. High volume developments are necessary to meet the backlogs. 


\subsection{HOUSING DEVELOPMENT CONSTRUCTION AND DATA CONTROL}

Traditional methods of development and building, although satisfactory in many respects, do not provide suitable answers to current demands in South Africa and other emerging economies.

Tight control of all aspects of development is essential if dwellings are to be delivered cost-effectively and rapidly.

In a typical exercise suitable land is initially identified. Services must be provided and statutory and local authorities must consent to the proposed development.

The Surveyor does a survey of the individual stands and registers the stands with the Surveyor General for approval of the Surveyor General Plan and the registration of the individual stands.

Such stands are then registered with the Registrar of Deeds only after it has been sold and the transfer takes place.

Individual stands for building locations are identified and dwellings are erected in accordance with approved plans.

Finance is generally required for each dwelling and supervision and control must be exercised over the construction of the dwelling.

Each dwelling is sold either before, during or after construction to a buyer. Financial and other details of the buyer must be recorded. If the dwelling has been financed by a financial institution then, essentially, the dwelling although occupied by a buyer, is subject to a bond or other form of control by a financial institution.

The preceding description of a typical development and building process is brief and deals only superficially with a large number of events which give rise to pertinent data relating to each dwelling.

Traditionally this data is stored in diverse locations, for example with a government or local authority, a developer, a builder, a financial institution such as a bank or building society, and with a buyer or owner of a dwelling. 
Each event or incident relating directly or indirectly to a dwelling generates additional data and usually requires existing data pertaining to the dwelling to be accessed.

The data load increases as events take place after completion of a development and building exercise.

The amount of data relating to a single dwelling is significant and the amount of data relating to a large number of dwellings which form the subject of a development undertaking is vast.

Hard copy plans required by the Nelson Mandela Metro is one example of the amount of information that can be associated with a large development. The required plans for Hillside in Despatch will have a mass of 5 tonnes and solutions are necessary to deal with this kind of phenomenon.

Substantial delays and inefficiencies result if existing data cannot be accessed rapidly or at all.

\subsection{ENERGY CRISIS}

South Africa is currently experiencing an energy shortage.

Architectural designs have been too lenient in the past, allowing mechanical and electrical means to correct mistakes made through design.

Little attention was given to embodied energy and life cycle/ running costs.

Traditional methods of electricity generation have become insufficient, and a more responsible approach is needed by designers to create buildings that have decreased energy consumption needs, or that are completely self-sufficient.

Buildings should use passive environmental control techniques to the maximum, where climate determines techniques used.

Alternative methods of energy such as solar power need to be implemented.

Due to the current world wide environmental crisis, architects have a responsi bility to create environmentally sustainable buildings. This includes water usage, energy needs and waste. 


\subsection{LOCALI TY VERSUS LAND AVAI LABI LI TY}

The locality of a development is very important in terms of sustainability i.e. transport, neighbourhood revitalization etc.

Government or Local Government land is very difficult to acquire by responsible developers and can takeyears.

Privately owned land for development in the right locations has become scarce and expensive. When it is acquired at these relatively high prices, special development measures have to be taken to still keep homes affordable and make acceptable returns.

Cosmo City which was a huge initiativeto cater for the lower sector, with time, has seen prices increasing and is once again becoming out of the reach of the normal working class.

\subsection{SHORTAGE OF SKI LLED LABOUR}

South Africa experiences a shortage of skilled workers in the affordable housing construction business since most skilled workers are drawn by the mega project boom leaving delivery of homes to unreliable contractors.

New home construction methods that can make use of unskilled labour have become necessary. The quality and aesthetics of such newly constructed homes should be the same or better than that done by conventional building methods to satisfy end user needs. Special architectural designs are needed and easier quality control and cost savings should be possible.

\subsection{END USERS IN THE AFFORDABLE MARKET SECTOR}

The affordable market is a special market different from the higher income market. Different marketing strategies have to be followed.

Prospective buyers are not easily reachable and have to be educated in terms of home ownership. 
For example, in the affordable market sector in South Africa, the average property transfer delay is 320 days from commencement of the first contact with the prospective buyer in comparison with the middle to high income sector which amounts to only 94 to 120 days.

\subsection{CONSTRUCTI ON OF TOP STRUCTURES}

Extensive research was done on alternative top structure construction methods since the cost of conventional building has increased to the extent that it makes it impossible for the lower income groups to purchase their own dignity home.

\section{SOLUTI ONS}

How we address the above-mentioned problems

\subsection{NNOVATI VE DESI GN MANAGEMENT}

Density

To counter act rising input costs, design for higher density can be applied to bring down stand/ unit costs without having to forfeit environmental quality.

Densities of 50 to 70 units per hectare versus 25 units should become the norm in South Africa rather than the exception. 


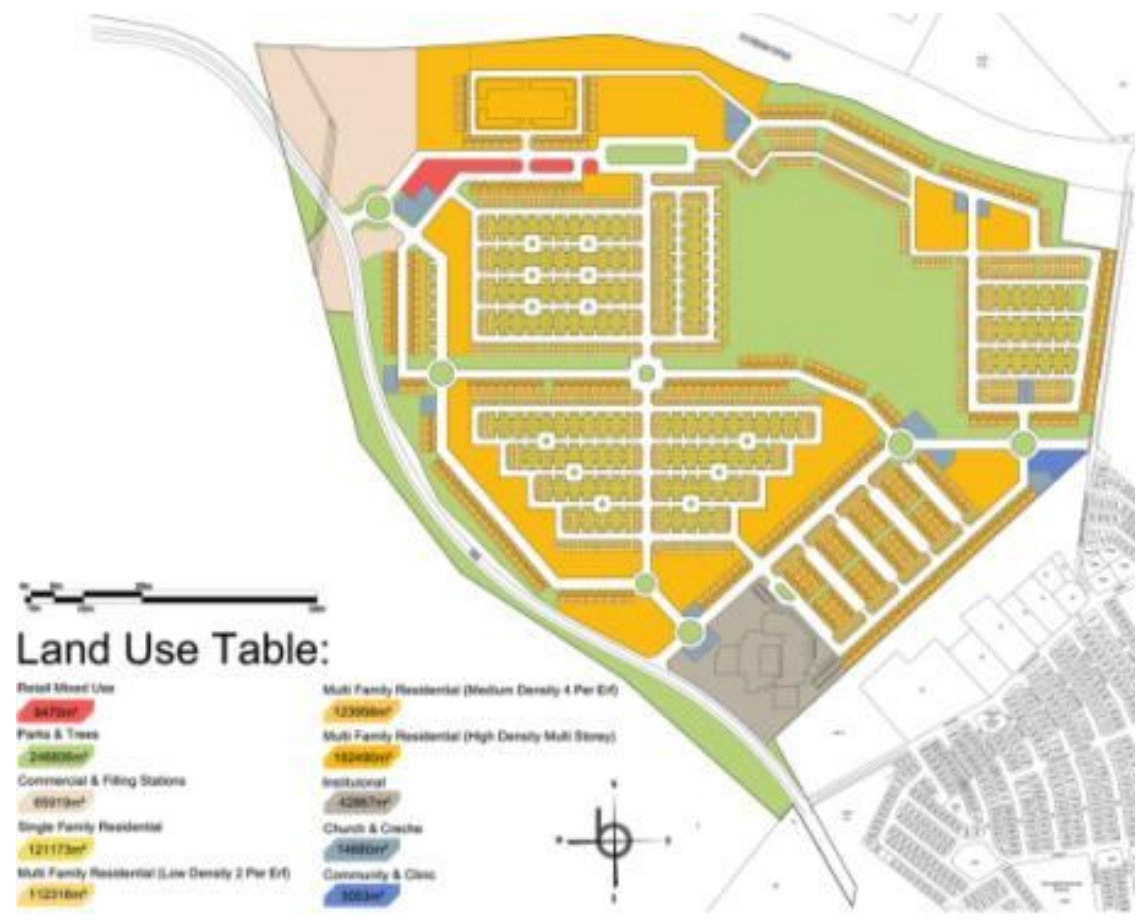

Figure 1: Urban Framework of Hillside in Despatch

This principle was applied in Hillside in Despatch in the Nelson Mandela Bay Metropole. To improve affordability, the number of units was increased from 3,700 to 5,390 - an average density of 45 residential units per hectare (121 hectares). Public open spaces and other development criteria induding environmental issues arestill in accordance with general development requirements of the Metro.

Top Structures: General

Taking economical and qualitative market factors into consideration, design of top structures becomes vital to meet all architectural requirements as well as at the same time makes provision for affordability and matching it with end-user preferences and sustainability.

The development team (Developer, Architect \& Town Planner) embarked on a strategy to meet the abovementioned criteria.

Top Structures: Construction (Solid concrete panel walling system)

After world wide research and careful consideration and trial construction we chose solid concrete panels (20mpa) to replace brick and mortar. The system can best be applied with standardized designs in large volume developments and 
which make quicker turn around time and lower costs possible without forfeiting any aesthetics or quality priciples.
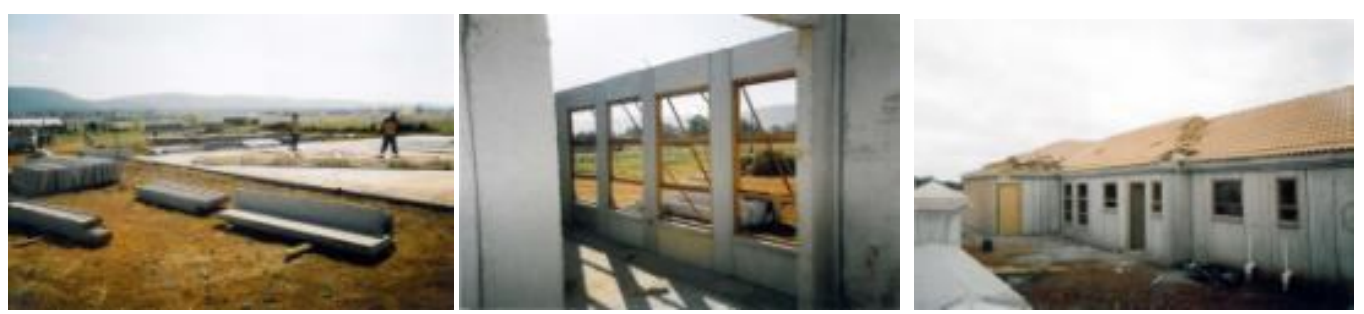

I mage 5-7: Solid Concrete Panel Walling System

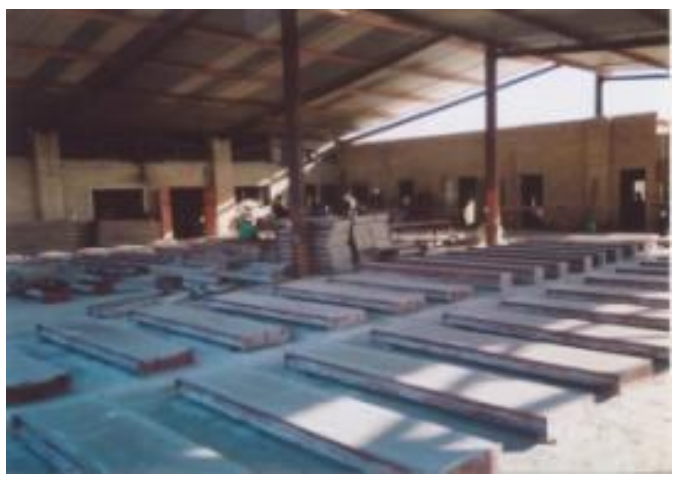

I mage 8: On-Site Concrete Panel Factory

Panels are manufactured on site in a process controlled environment with our own cement silos and batching plants.

Construction thus becomes a manufacturing and assembly process that is superior in terms of all aspects of control.

Top structures: Space-Key H ome ID applications

The Space-key Home ID central data base with its control abilities will enable one to manage the control of large developments, security villages, body-corporates and home owners associations.

Should we take Hillside in Despatch for example the following is planned and will be made possible:

- Identification for each unit - homeID

- Home owners associations for different super blocks (20 to 30 units)

- Regulation of all conditions incorporated in sales agreement.

- Data base linked to home ID 
- Home ID linked to home owners association.

- Water and electricity readers linked to home ID

- Electricity and water usage logged in space-key

- Energy savings logged in spacekey

- Controlled extensions of units and many more (expansion).

- All units to beenergy efficient with up to $40 \%$ energy savings

Correctly planned and organised a single large development with the size of Hillside in Despatch will be phased into the maximum time frame of just more than three years completing 200 units per month and using 10 sets of panel production moulds.

Top Structures: Phased Incremental U nits

Phased incremental units were designed to increase the range of affordability and allow end-users to enter the market in accordance with their income and loan qualifications as well as to make extensions possible in an organized manner; not losing the character of a particular development.

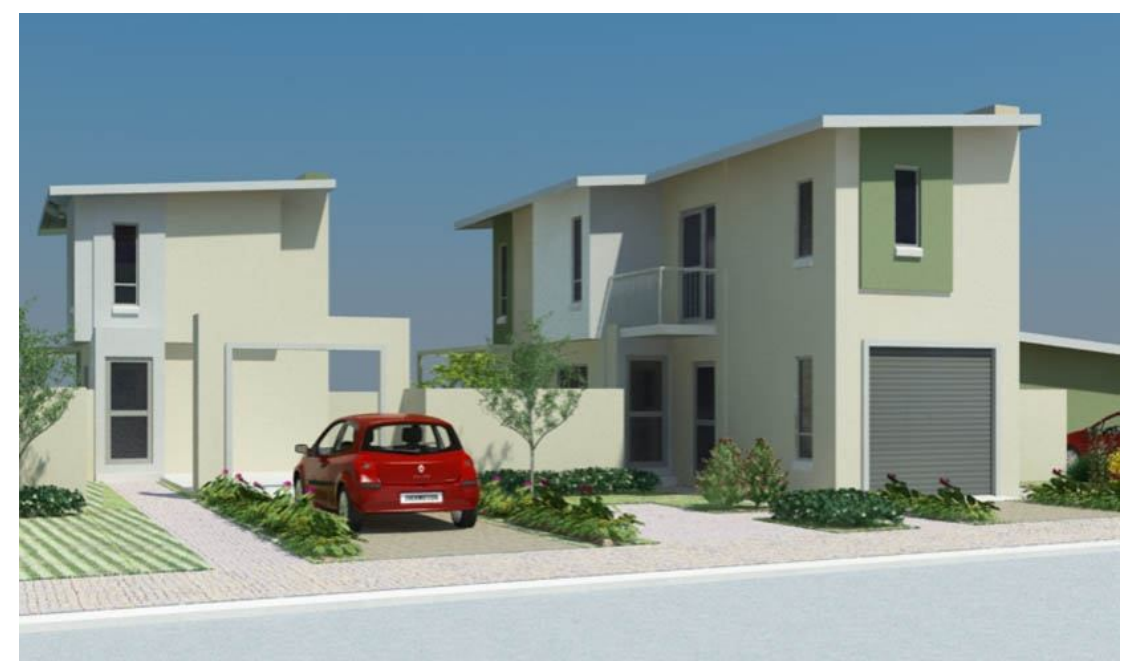

Figure 2: Phase 1 - 57m2 (Left) \& Phase 2 - $99 \mathrm{~m} 2$ (Right)

Versatile spaces are incorporated in the designs that could double as rental rooms, spaza shops etc. to increase affordability and density and to create secure environments within larger developments. 
Top Structures: Passive Energy Design:

There are a number of passive design methods that can be implemented to create a building with low energy needs. Of the most important factors to consider are climate influences and sun-angles. The selection and combination of different principles are project specific. All units are passively designed to conserve energy

Top Structures: U nit D esign Principles

Design principles applied include the following:

Top Structures: D esign Principles - General A rchitectural A pproach

In the first instance a very close relationship is to be maintained with the developer who has to have the vision and willingness for innovation and change.

The approach is to design high density units with a sense of dignity and privacy. Something one can be proud of. We aim to create a place where people feel that they belong.

The sustainability of these projects depends on volume. The projects need to be high volume developments of 1,000 units and more.

We try to ensure that people do not get lost among the numbers by using simple techniques that ensured responsible and successful housing all over the world and for many years.

The process starts with the town planning layout and ends in the small details of the building.

It is important that the developer also notice and accept the value of adding these principles that we apply, in order to create a sense of place within the urban fabric.

Top Structures: D esign Principles - O rientation

Orientation with optimum use of:

Natural light and direct solar gain in winter and shading in summer Glazing positions and openings and overhangs.

Provision is made for insulation in ceiling space. 
Natural ventilation and lighting is utilized to its optimum.

Top Structures: D esign Principles - Lower Electrical Demand (A pplied)

Methods used to lower electrical demand include:

Installation of solar water heaters and central heating systems

Low energy fittings

Gas used for cooking

With the above measures a savings of $45 \%$ energy is achieved.

Top Structures: D esign Principles - 0 ther M ethods (To be applied)

Other methods used to lower the environmental impact of a building are:

Rain water collection

Grey water recycling

Black water disposal - septic tanks and French drains

Recycling projects

Promotion of urban agriculture

Top Structures: 0 ther Principles - Services

Minimized cost for services, with economy of the design and town planning layout, should bethe goal.

Top Structures: 0 ther Principles - Street Front

Streets are designed with the emphasis on pedestrians and cyclists with cars coming second.

Top Structures: Other Principles - Privacy

Privacy is an important key to the success of a high density development and needs very careful consideration in terms of the design. In this sense the saying of "good design does not cost more money" is very true.

Top Structures: O ther Principles - Social Formation 
Social formation is an important consideration especially in the case of larger projects. Super blocks are erected with land owners associations of 20 to 30 units within such blocks.

Top Structures: 0 ther Principles - Sustain ability

In the affordable market sustainability needs to be considered in every development in terms of different time frames of social interaction as well as in terms of economical factors during and after completion of the project.

Top Structures: 0 ther Principles - Interface

Surveillance of the street is created by creating balconies and porches. The street should be a friendly place where people live. We believe there is no better security than as many eyes as possible watching the street. Neighbours need to know each other and together take ownership of their environment.

We aim in our designs to create communal safe areas as well as to comply with the traditional requirement to make it easy for dwellers to stay in contact with their neighbours and theneighbourhood in general.

Top Structures: Other Principles - A ffordability

Affordability is probably the most important issue that needs attention first and foremost but we do not sacrifice dignity and good design to achieve affordability.

Top Structures: O ther Principles - M aximising Income Generating Possibilities

We endeavour to create vibrant neighbourhoods that can sustain themselves. For instance garages can double as spaza shops during the day if one has provided alternative parking for cars in the development.

A number of units are in addition designed with a combination of residential and shopping space.

In our designs we try to make provision from the outset for the construction of rooms that could be rented out to create income. This approach assists to prevent the building of shacks in the back yard for rental purposes.

Top Structures: 0 ther Principles - I dentity 
Everybody wants his own address that is not only a number on the wall but something that is different and can be referred to.

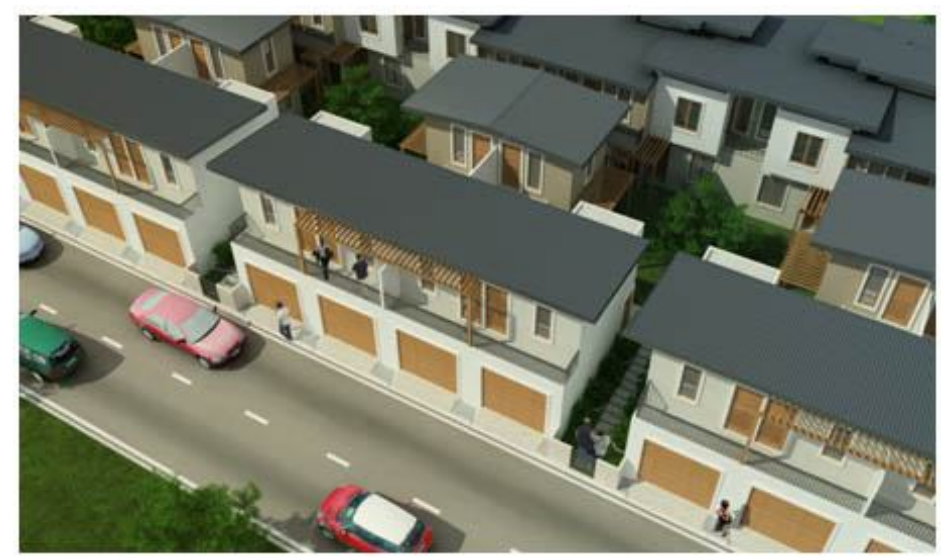

Figure 3: 4 Units, 1 Entrance, Communal Courtyard \& Rental Rooms on top of Garages

An address can easily be provided through careful detailing without increasing costs

\subsection{DEVELOPMENT CONSTRUCTION AND HOME DATA CONTROL} General

High volume developments need special control mechanisms.

An electronic information process and quality control system was developed to uniquely identify a particular dwelling. (Provisional Patent No. 2007/ 08825).

This system is used to collect and store information and also control various aspects of the development process as well as historical data which arises after completion of the process when occupation has taken place and when the home is normally owned by way of a bond held by a financial institution.

Process D escription

Each house is equipped with a Radio Frequency Identification (RFID) device. The RFID contains a unique identification code and has the capability to store limited data. The unit is enclosed in the foundation of the house.

The RFID Reader is used to read data and the unique identification code on the RFID tag. 
The RFID reader has the following features:

Incorporates a microprocessor, which allows the development of custom user applications.

User interface to capture and display data.

Read and write RFID tags.

GPS receiver to confirm location

GPRS/ 3G connectivity via the GSM network.

Interfaces with data capturing devices e.g. camera.

The data which is acquired at a housing structure is downloaded in real-time to a Housing Project Server via a secure link on the GSM network. The data is maintained in a database and users are able to access the data via a WEB browser, using a secure Internet protocol.

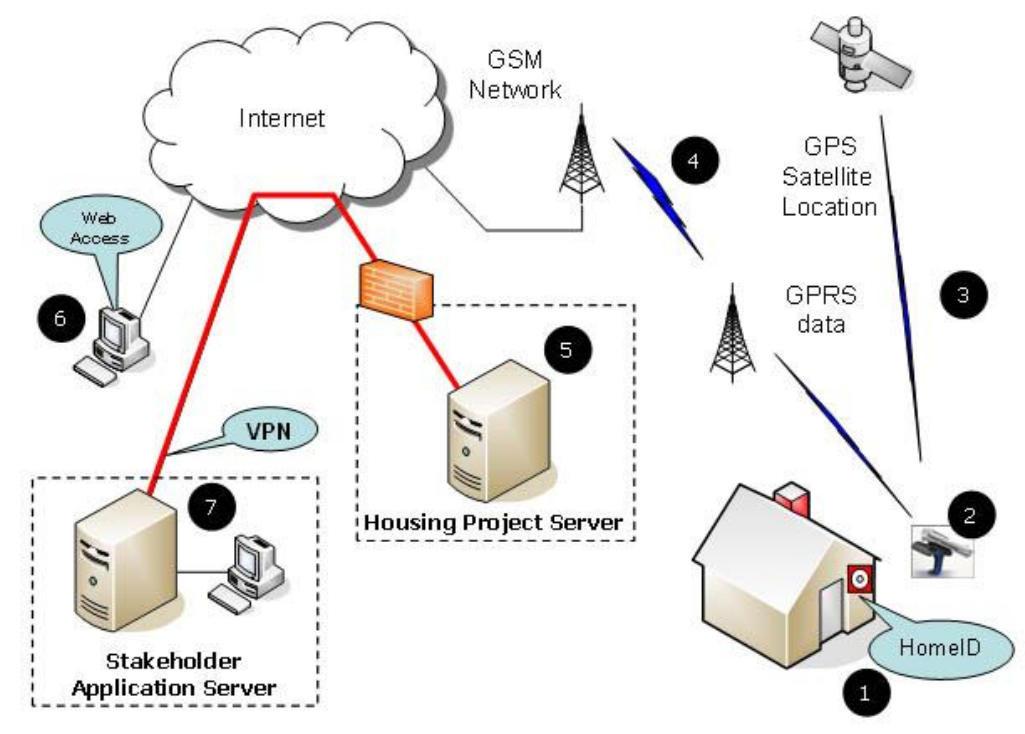

Figure 4: Network Architecture

Stakeholders in the housing projects will be able to interface with the Housing Project Server via Virtual Private Networks (VPN).

\begin{tabular}{|l|l|l|}
\hline 1 & $\begin{array}{l}\text { House } \\
\text { Registration }\end{array}$ & $\begin{array}{l}\text { An RFID is installed in the appropriate position at each } \\
\text { house which needs to be registered on the HPMS. } \\
\text { RFID reader reads the RFID code and acquires the GPS } \\
\text { coordinates of the house which is registered. }\end{array}$ \\
\hline
\end{tabular}




\begin{tabular}{|c|c|c|}
\hline & & $\begin{array}{l}\text { RFID code \& GPS coordinates is transferred to Housing } \\
\text { Project Server. } \\
\text { The RFID Reader writes the GPS coordinates and other } \\
\text { TBD data to the RFID tag. }\end{array}$ \\
\hline 2 & Data Capturing & $\begin{array}{l}\text { A house is identified by reading the RFID code using a } \\
\text { RFID Reader. } \\
\text { The data capturing session is authenticated by the } \\
\text { Housing Project Server, using the identification code } \\
\text { and GPS coordinates. } \\
\text { Data is captured using a data entry form on the RFID } \\
\text { reader or data capturing devices. } \\
\text { The captured data is transferred to the Housing Project } \\
\text { Server. }\end{array}$ \\
\hline 3 & $\begin{array}{l}\text { Access } \\
\text { development } \\
\text { project } \\
\text { information }\end{array}$ & $\begin{array}{l}\text { Users can access the information maintained in the } \\
\text { Housing Project Server via a Web browser interface. } \\
\text { Data can be viewed, exported or printed from the web } \\
\text { browser. } \\
\text { Data entry is possible from the Web browser. }\end{array}$ \\
\hline 4 & $\begin{array}{l}\text { Off-line data } \\
\text { retrieval. }\end{array}$ & $\begin{array}{l}\text { RFID Reader is used to retrieve data stored on the RFID } \\
\text { tag. }\end{array}$ \\
\hline 5 & $\begin{array}{l}\text { Integration with } \\
\text { housing project } \\
\text { stake holders. }\end{array}$ & $\begin{array}{l}\text { Stake holder software applications interfaces with the } \\
\text { Housing Project Server via a VPN and housing project } \\
\text { information will automatically be retrieved. } \\
\text { The integration of the Housing Project Server will be } \\
\text { able to supports work flow processes of stake holder } \\
\text { applications }\end{array}$ \\
\hline
\end{tabular}

Table 1: Workflow Overview

\subsection{SYSTEM FEATURES}

Space-Key Home ID - General

The system is particularly suited for use in high volume developments. The many features of the system are as follows:

In a typical development exercise a developer identifies suitable land for development. Title deeds are checked and plans are obtained from the surveyor general. The geographical coordinates of the land in question are validated.

In any appropriate sequence the following activities are carried out: 
An environmental impact assessment program is conducted;

A town planner is appointed;

A sub-division survey is carried out by a qualified land surveyor. The surveyor general is approached for approval of the sub-division of the land in question. The approved surveyor general's plan is logged and thereafter stand boundaries are identified.

The developer draws up and implements a development program;

An architect is appointed. The architect, in respect of each site, prepares a site plan and this is submitted to the local authority for approval. The site plan is logged;

civil and electrical engineers are appointed to do bulk reports, prepare reticulation plans for services such as water, sewerage, and electricity, to negotiate rights of way where necessary, and to obtain approval from the local authority for the intended services; and

A contractor is then appointed to implement the construction program.

Up to this stage data which is generated is in respect of a structure which is to be erected i.e. a virtual structure. The data is comprehensively logged in a suitable storage mechanism which is uniquely associated with the structure which is to be built. In this situation the structurecan be conveniently identified with reference to the Surveyor General stand number of a site on which building is to take place. Activities which subsequently arise relate to the erection of the structure and include the following:

Site meetings typically between project managers and the building contractors and engineers. These give rise to progress reports;

Inspections by local authorities and regulatory bodies e.g. electrical and home construction inspectors;

Architect supervision, etc;

Inspections by a financing institution; and 
Attending to snag lists such as remedial work to overcome defects and to ensure full compliance with initial approved working plans.

A third category of activities relates to financial and sales aspects. Thus a potential buyer would approach a financial institution for finance to purchase the structure. A rising therefrom the financial institution would inspect the structure and make an assessment of the viability of a loan to the potential buyer. Depending on the outcome of such investigations finance can be made available and agreements are conduded between the respective parties.

Subject to guarantees being made available by the financial institution, a conveyancer is appointed to register the transfer of the property in question to the buyer and to register a bond over the property in favour of the financial institution.

Statutory or regulatory requirements are attended to.

A large number of individual quality control and inspection visits takes place. The building progress is monitored and quantities of building material delivered to the building site and used in the building activity are tracked. Inspections typically include the following: foundation inspection, rational design inspection, an inspection by a bank or financial institution which provides finance for the building activity, municipal inspections, and inspections for the issuing of compliance certificates. Service connections are made to water supplies, electrical supplies and sewerage outlets. Finally an occupation certificate is issued and the buyer is lawfully entitled to occupy the structure.

Financial and historical information and pertinent details relating to a structure typically include the following: the name and address of the institution which finances the structure, the number of each bond which is registered over the property, the name and identity details of the buyer, the buyer's physical address, full details of the title deeds relating to the property in question, data relating to NHBRC enrolment particulars, stand number, SG (surveyor general) plan, boundary points, a full copy of the original plan and a copy of any plan approved and used after completion for extension or repairs and modifications to the structure or for reticulation purposes or the like. 
It is apparent from the aforegoing that a substantial amount of data is generated. This data should be accessible with ease and rapidly when required. To meet this objective a centralised repository of data is called for. A further factor is the need to associate the repository of data uniquely and unmistakeably with the structure. Our system offers two solutions to the aforementioned requirements. In the first instance the data in question is stored in a storage device e.g. a hard disc or semiconductor memory which is offsite. A unique key is however required in order to read or write data to the storage device. That unique key, which may be electronic in nature, is physically attached to the structure. The data in the key can only be accessed by means of a physical or an electronic visit to the structure. Thus when the key is available the data which is accessed is automatically, directly and uniquely associated with the structure in question.

In an alternative approach the storage mechanism is, itself, physically attached to the structure. Thus, again, the data, when accessed, is automatically and uniquely, directly associated with the structure in question.

In each approach the key or the storage device, as the case may be, is attached to the structure using a physical link e.g. the key is embedded in a container which in turn is embedded in the foundation of the structure.

The information on the storage device is highly relevant to the developer during the planning and construction stages. Subsequently, however, once the developer has been paid for the structure the information contained in the storage device is of greater importance to the buyer of the structure on the one hand, and to the financial institution, on the other hand. Details of the owner are also logged in the storage device. It is appropriate therefore to ensure that the financial institution is placed in a position to safeguard the integrity of the data i.e. control of the storage device would usually be passed to the financial institution until such time as the financial institution no longer has an interest in the structure. This event would normally take place when the bond over the structure has been paid off by the buyer. At that stage control of the storage device should pass to the buyer.

Should the buyer wish to sell his dwelling before the bond has been liquidated in full, the financial institution can be instructed to make information available to the 
home owner or to a sales agent to enable the home owner to sell the house. Control of the storage device will then go to the new bond holder or to the new owner if no bond is involved.

Extensions could be approved at the plan approval stage by the local authority and financial institution and only an increase in the bond amount can trigger automatically the extension process.

It is pointed out if any extensions are to be made to the structure that the necessary background information required in support of an application for approval is readily obtained from the storage device. Information relating directly to the extension, once the extension has been approved, should be transferred to the storage device.

In this particular instance we will focus and demonstrate only one feature of the system and that is the system being used for integrated inspection and control by project managers, subcontractors, engineering, architects, government and local authorities as well as financial institutions.

System features - Inspections monitoring with Space-key

Inspections are done by the following professionals and authorities during a development:

- Engineering

- QS

- Architect

- Project Manager

- NHBRC

- Municipality

- Financial Institutions

Inspections are difficult to co-ordinate and control as well as to ensure that reports are accurate and trustworthy. The problems are experienced by the developer as 
well as by the authorities and the financial institutions. Rework is costly and time delays in progress payments can put severe pressure on cash flows.

\section{EXECUTION / TECHNOLOGY \\ SPACE-KEY \\ INTEGRATED HARDWARE \& SOFTWARE SYSTEM}
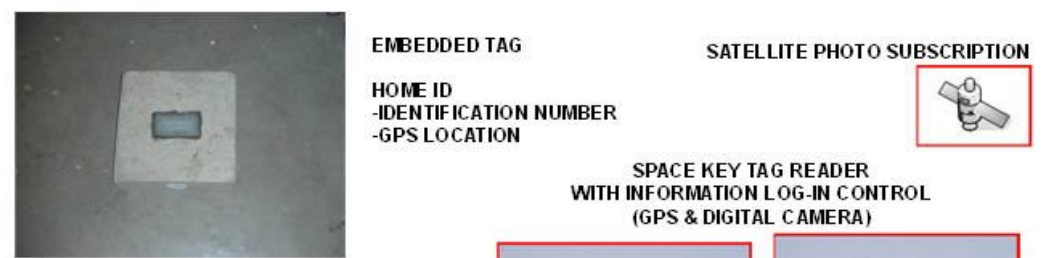

-IDENTIFICATION NUMBER

SPACE KEY TAG READER

WITH INFORMATION LOG-IN CONTROL (GPS \& DIGITAL CAMERA)
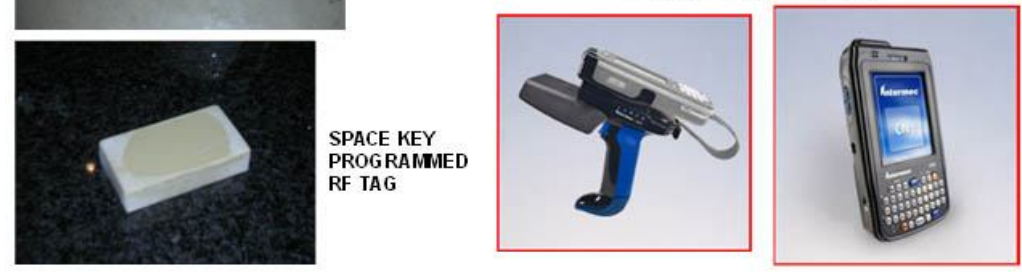

Figure 5: Programmed Hardware

System features - Low Cost H ousing Inspections monitoring with Space-key

An example of the monitoring abilities of Space-Key in the subsidized low cost sector (RDP) can be described as follows:

STEP 1: D efine e-space homes project

Project number and name Geotechnical detail

Project layout Inspection stages

Virtual home location Certification criteria

House plan detail $\quad$ Project manager

Service level Professional engineer

Subsidy administrator

STEP 2: Pre-devel opment site verification

Site satellite photo verification

Stand satellite photo verification

Physical verification of occupant information 
Log specified information requirements

Confirm photo with device controlled built-in camera

Upload information to space-key database

STEP 3: Independent quality control

Inspections via GPS-coordinated handheld device

Device controls built-in camera

Inspector prompted to:

- Read home ID

- Select Project Name

- Log stand number

- Select stage of inspection

- Log findings

- Select inspector'sID number

Photo only possible after specified criteria werelogged

Photo and associated data uploaded to space-key database

Space-key automatically generates progress payment certificate

Lastly one other example of the many features of the system is the integrated control of the conveyancing process. This factor has historically been ignored to a large extent and will now be addressed by the system. In the affordable market sector in South Africa as mentioned above the average transfer delay is 320 days. This should be brought in line with the delay of the middle income group.

The buyer and all other professions are involved in the conveyancing process. Total integrated information and process control with the system will bring transfer delays down to a level much closer to that of the higher income sectors with a result of much faster delivery and substantial cost savings.

\subsection{SUSTAI NABI LITY}

Locality and job creation 
A mongst many other factors locality and job creation are very important issues to deal with in the planning and execution of developments.

Home owners spend up to $25 \%$ of the income on transport and we rather purchase more expensive land near the workplace and deal with affordability in different ways than having land with not such good locations.

The contruction process makes the use of unskilled labour possible. Employment is in addition created over a longer period of time and eventually construction workers will belicenced to establish their their own business units.

\subsection{BALANCING ACT}

In conclusion a balance needs to be found between cost increases, affordability, preferences, delivery and sustainability on one side and research, design density, locality, environmental quality and volume based developments on the other side.

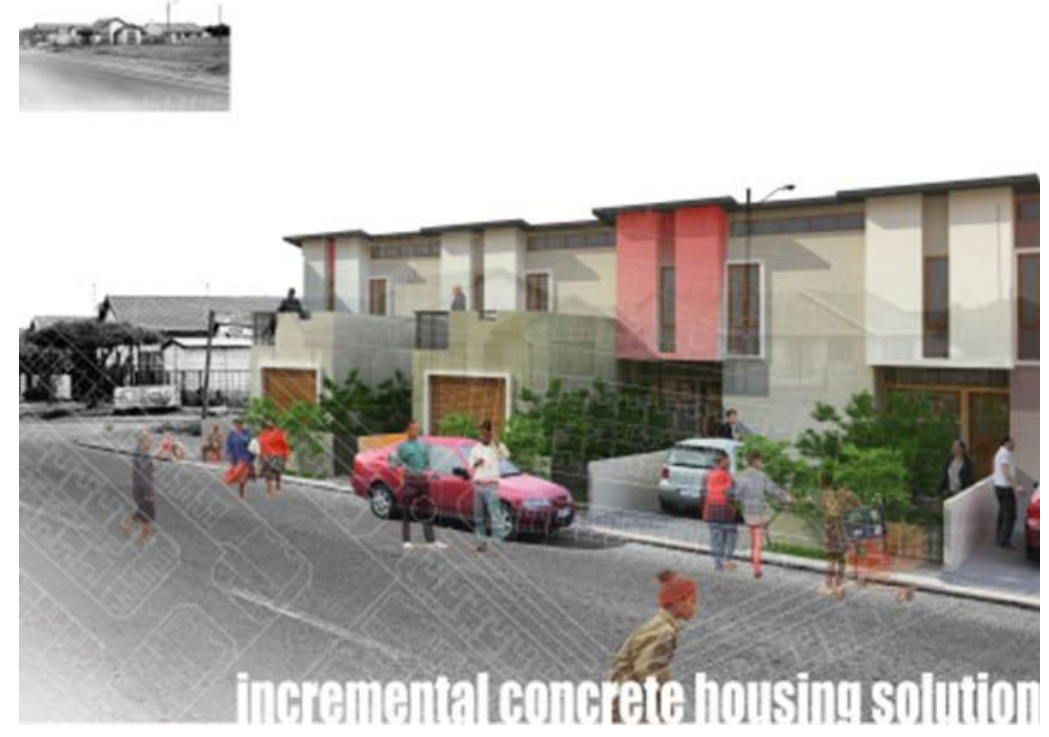

I mage 9: Urban Renewal at it's best! Creating a Sense of Place 


\section{LI TERATURE}

CHARLES, C., Housing and Urbanization: Building Solutions for People and Cities, Thames \& Hudson, 2000.

CONGRESS FOR THE NEW URBANISM, Charter of The New Urbanism, McGrawHill Professional, 1999

DuAnY, A. PLATEr-ZYBeRCK, E., Towns and Town-Making Principles, Rizzoli, 1991

FARR, D., Sustainable Urbanism: Urban Design With Nature, Wiley, 2007

GRANT, J., Planning the Good Community: New Urbanisms in Theory and Practice (The Rtpi Library Series)

KATZ, P., The New Urbanism: Toward an Architecture of Community

MCCARTHY, D., DYODO, S., POTGIETER, S., LARSSON, S., TYRSTRUP, O., Sustainable Community Planning Guide, 2007

SPIRN, AW., The Granite Garden: Urban Nature And Human Design 